confer activity upon the other. It will be particularly interesting to see how these proteins relate to the membrane changes in the mutant cells found some time ago by Siccardi, Shapiro, Hirota and Jacob (J. Mol. Biol., 56, 475; 1971).

Although rifampicin fails to inhibit replication of $\phi \times 174$, actinomycin D does so in vitro, as does deprivation of the four ribonucleoside triphosphates. RNA seems to be covalently linked to DNA in the product of replication. This supports the idea that RNA may be involved in the initiation of $\phi \times 174$ replication, although previous attempts to implicate it have failed. This means that both M13 and $\phi \times 174$ may use similar, although not identical, mechanisms. The insensitivity of the $\phi \times 174$ process to rifampicin suggests that some enzyme other than the usual RNA polymerase may be implicated in providing RNA used for initiation, as indeed it may be involved in starting off the Okazaki fragments of bacterial DNA (see Nature, 239, 7; 1972).

Turning to higher organisms, Stavrianopoulus, Karkas and Chargaff (ibid., 2609) report further studies on the DNA polymerase which they have purified from chicken embryos. This is a small enzyme-the smallest DNA polymerase yet isolated-of only some 27,000 daltons. As this enzyme also requires the mediation of RNA as a primer for replication, it seems likely that RNA priming may be used by many, if not all, replicating systems to start off DNA synthesis.

\section{SEAFLOOR SPREADING}

\section{Scotia Axis Confirmed}

from our Geomagnetism Correspondent SMall though it is, the Scotia Sea, which lies between South America and Antarctica, has been a happy hunting ground for geophysicists for several years. It is bounded on the east by the curved South Sandwich Island arc and trench, on the north by the North Scotia Ridge which reaches westward from the northern end of the arc-trench to the tip of South America, and on the south by the South Scotia Ridge which stretches westward from the southern tip of the arc-trench to the Antarctic Peninsula. It has usually been regarded as a remnant of the Pacific plate, even though the two components of the Scotia Ridge are only slightly active seismically and thus not particularly typical plate boundaries. The arctrench system, on the other hand, is intensely active, the seismicity being consistent with a descending lithospheric slab dipping to the west. The older exposed basaltic volcanics on the South Sandwich Island have been dated in the range 0.7 to 4.0 million years, which ties in with Baker's view
(Bull. Volc., 32, 189; 1968) that the island represents a very early stage in the evolution of an oceanic island arc.

The simple picture of the Scotia Sea as a crustal remnant resisting the westward motion of South America and Antarctica is, however, inconsistent not only with the lack of seismicity along the northern and southern edges but also with a preliminary magnetic analysis by Barker (in Antarctic Geology and Geophysics, edited by R. J. Adie; 1971) which concluded that the Scotia Sea was formed almost entirely during the past 40 million years. Moreover, Barker's data complicated the picture even more by suggesting the presence of an active spreading centre, trending slightly west of north, to the west of (that is, behind) the arc-trench. Barker thus concluded that the region between the arc-trench and the newly postulated spreading axis forms a separate small plate (the Sandwich plate) growing and spreading eastwards at a rate of about $5.4 \mathrm{~cm} \mathrm{yr}^{-1}$ (the half spreading rate at the axis being $2.7 \mathrm{~cm}$ $\left.\mathrm{yr}^{-1}\right)$.

Because the quality of the original data was poor, Barker has revisited the scene to acquire better results with which to examine the proposed spreading centre (Earth Planet. Sci. Lett., 15, $123 ;$ 1972). The new data, based on several east-west traverses across the north-south magnetic anomalies, confirm the presence of the postulated spreading centre. Moreover, a detailed analysis of the anomalies shows, first, a variable spreading rate with a minimum around 2 million years ago, second, an overall acceleration of the spreading rate from 5 to $6 \mathrm{~cm} \mathrm{yr}^{-1} 4$ million years ago to 7 to $9 \mathrm{~cm} \mathrm{yr}^{-1}$ today, and third, that during the past 4.5 million years at least, the spreading in the north has been significantly asymmetrical. It seems that during this period the spreading rate to the east of the axis has been greater than to the west. A similar asymmetry is also observed in the south out to 2.0 million years; but beyond 2.0 million years in the south and 4.5 million years in the north the data are not precise enough either to resolve any asymmetry or to exclude it.

As Barker points out, there is no reason to suppose that the motions over the rest of the Antarctica-South America boundary are anything but slow, nor any reason to suggest that relative motion is now occurring across the North Scotia Ridge. The conclusion must therefore be that the relative motions at the spreading axis and the trench are directly complementary, and thus that trench and axis form the leading and trailing edges, respectively, of a small separate lithospheric plate growing at its western edge and moving eastwards relative to South America at a rate of 7 to $9 \mathrm{~cm} \mathrm{yr}$.

But the reason for this equality, which seems to be necessary in terms of the plate tectonic relationships in the area, is not immediately clear because the axis and trench are not part of the same spreading system in the sense that, say, the East Pacific Rise and the Aleutian Trench are. Barker's spreading axis lies

\title{
X Linkage of Human Galactosidase
}

MEN who suffer from Fabry's disease are deficient in the enzyme galactosidase and their mothers either have a normal amount of this enzyme or are also deficient in it. These findings indicate that a deficiency of this enzyme is the result of a mutation linked to the $\mathrm{X}$ chromosome ; they do not, however, prove that the structural gene for a galactosidase is X-linked and indeed in some mammals, horses and donkeys, the galactosidase gene is autosomal. To find out whether or not this is the situation in man Grzeschik and eight collaborators in the United States, Germany, Italy and Holland have used the by now familiar technique of interspecific somatic cell hybridization. And as they report in next Wednesday's Nature New Biology (November 8) their experiments show that in all probability human galactosidase is X-linked.

Grzeschik et al. fused Chinese hamster cells deficient in thymidine kinase with human diploid fibroblasts lacking hypoxanthineguanine phosphoribosyl transferase and used HAT medium to select hybrids. They then screened the hybrid cells for the presence of human galactosidase and three other human X-linked markers, and for three human autosomal markers during their cultivation in appropriate media. In summary they found that hybrid cells which retained human galactosidase also retained the three X-linked markers, and that loss of galactosidase correlated with loss of these three markers. By contrast segregation of galactosidase was independent of the segregation of the three autosomal markers. The simplest interpretation of these and other data is that the galactosidase structural gene(s) is X-linked in man.

Chasin, as he reports in next week's Nature New Biology, has also used the technique of somatic cell hybridization to investigate the linkage relationships of induced mutations of Chinese hamster cells, and he has reached the conclusion that at least three of the recessive mutations and their wild type alleles that he has studied are not in any way linked. 